\title{
Genetic heterogeneity and mitochondrial DNA heteroplasmy in Leber's hereditary optic neuropathy
}

\author{
I J HOLT, D H MILLER, AND A E HARDING \\ From the University Department of Clinical Neurology, Institute of Neurology, London WC1N $3 B G$.
}

SUMMARY Analysis of mitochondrial DNA from patients with Leber's hereditary optic neuropathy and their relatives showed that the previously reported mutation at base pair (bp) 11778 , shown by loss of a recognition site for the restriction endonuclease $S f a \mathrm{NI}$, was present in only four out of eight families. This mutation was associated with a poor prognosis for visual recovery, whereas four of five affected males without the $11778 \mathrm{bp}$ mutation followed for four years or more had regained useful vision. All but one of the subjects showing the SfaNI site loss had a variable mixture of mutant and normal mitochondrial DNA in peripheral blood, and the relative proportions appeared to be correlated with the risk of developing or transmitting Leber's hereditary optic neuropathy.

Leber's hereditary optic neuropathy (LHON) gives rise to acute or subacute blindness, usually in young adult males. Loss of visual acuity is generally severe (6/60 or less) and persistent, although limited improvement is sometimes observed. ${ }^{12}$ LHON is transmitted exclusively through the maternal line; in contrast to $X$ linked inheritance, the descendants of affected males are never affected. Between 70 and $100 \%$ of the daughters of female carriers transmit the disease to their sons, and 50 to $100 \%$ of the sons of carriers develop LHON. About $85 \%$ of patients with LHON are male, and $18 \%$ of female carriers are affected. ${ }^{2} 3$ These observations are compatible with the hypothesis that the disease may be caused by mutation of mitochondrial DNA (mt DNA). ${ }^{34}$

Human mt DNA is a closed circular molecule 16569 base pairs (bp) in length, which is only transmitted by females; it has been entirely sequenced and is known to code for 13 polypeptides of the mitochondrial respiratory chain and oxidative phosphorylation system. ${ }^{5-9}$ Defects of the mitochondrial genome have been described in some patients with mitochondrial myopathies, a heterogeneous group of disorders that exhibit an excess of maternal transmission. ${ }^{10-12}$ More recently, Wallace et $a^{13}$ reported a point mutation at position 11778 of mt DNA in members of nine out of 11 LHON pedigrees; this was not present in 45 control subjects. The mutation led to an amino acid change from arginine to histidine in a subunit of NADH CoQ reductase (ND4). The mutation was present in all maternally related subjects in these families, regardless of whether or not they were affected. It also appeared to be homoplasmic, that is, present in all mt DNA molecules analysed.

The change from adenine to guanine at position 11778 in mt DNA results in loss of a restriction site for the restriction endonuclease SfaNI. ${ }^{6}$ Using this observation we have investigated eight LHON families in the UK; our findings differ from those of Wallace $e a^{13}$ and these differences appear to be clinically significant.

\section{Patients and methods}

PATIENTS

Three groups of subjects were studied: (1) 13 patients (11 males and two females) with LHON from eight families; (2) 15 unaffected matroclinal relatives from these families, including four obligate carrier females (with two affected sons or an affected son and brother or nephew), six males at risk of being affected (with affected brothers and maternal uncles/cousins), and five females who were potentially carriers (with one affected son or affected brothers/nephews); and (3) 27 normal control subjects.

LHON was diagnosed using the following criteria: (1) subacute bilateral visual failure developing between the ages of 12 and 50 years; (2) examination in the early phase of the illness showed characteristic fundal changes (disc swelling, peripapillary telangiectasia) and bilateral centrocaecal scotomas in at 
least one family member; (3) other causes of optic neuropathy (for example, compressive lesions, toxins, vitamin B12 deficiency) were excluded; and (4) there was a family history of a similar disorder without paternal transmission. The first three criteria were fulfilled in all 13 cases and 12 had affected relatives. The two females both had affected brothers.

\section{METHODS}

DNA was extracted from $20 \mathrm{ml}$ blood using standard techniques $^{14}$ and $1 \mu \mathrm{g}$ samples of DNA were digested with up to five units of $S f a \mathrm{NI}$ under conditions recommended by the manufacturers (New England Biolabs) with the addition of bovine serum albumin and spermidine. DNA fragments

b

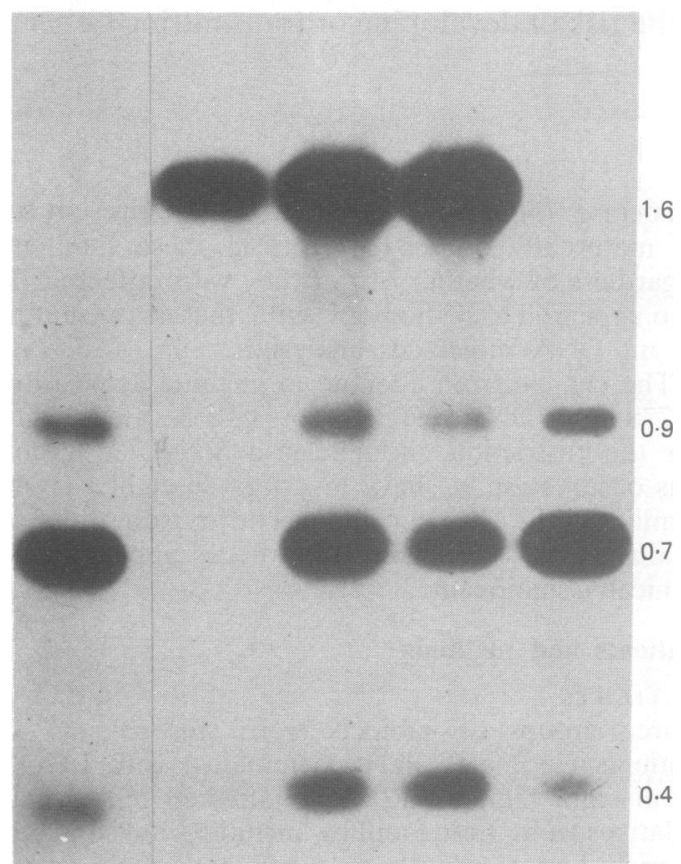

FIG 1 Restriction fragment patterns after digestion of DNA with SfaNI and hybridisation to a fragment of HeLa cell mt DNA (11680 to $12570 \mathrm{bp})$ : (a) normal control shows fragments $0.9,0.7$, and $0.4 \mathrm{~kb}$ in length; $(b)$ in a male with LHON the 0.7 and $0.9 \mathrm{~kb}$ bands are replaced by one of 1.6 $k b$ owing to loss of the SfaNI restriction site at 11778 bp; in lanes $c$ and d (one unaffected male at risk and one possible carrier female) there is a mixture of mutant and normal $\mathrm{mt}$ $D N A$, shown by the presence of $1 \cdot 6,0 \cdot 9$, and $0.7 \mathrm{~kb}$ fragments; in lane e, another male with LHON, the SfaNI site is retained. In lane $b$ there was an additional faint band of $0.7 \mathrm{~kb}$ on the autoradiograph and this was easily visible after longer exposure. were separated by horizontal agarose gel $(1.7 \%)$ electrophoresis for 16 hours at $34 \mathrm{~V}$ and then transferred to nylon membrane (Hybond-N, Amersham, UK) by Southern blotting. A fragment of Hela cell mt DNA (11680 to $12570 \mathrm{bp}$ ), cloned in $\mathrm{M} 13$, was labelled ${ }^{15}$ with ${ }^{32} \mathrm{P}$ before hybridisation to the filters under conditions recommended by Amersham. Washes were: $2 \times \mathrm{SSC}$ for 50 minutes (twice), $2 \times \mathrm{SSC}, 0.1 \%$ SDS for 30 minutes, and $0 \cdot 1 \times \mathrm{SSC}$ for 10 minutes, all at $65^{\circ} \mathrm{C}$. Fragments were visualised by autoradiography for eight hours to 10 days at $-70^{\circ} \mathrm{C}$. The relative proportions of the 1.6 and $0.7 \mathrm{~kb}$ mt DNA fragments were assessed using an LKB Ultroscan densitometer. Owing to different exposure times and loading between samples, it was not always possible to obtain accurate densitometric measurements of these proportions. Accordingly, the proportion of mutant $\mathrm{mt}$ DNA was estimated as greater than $95 \%$ in some cases.

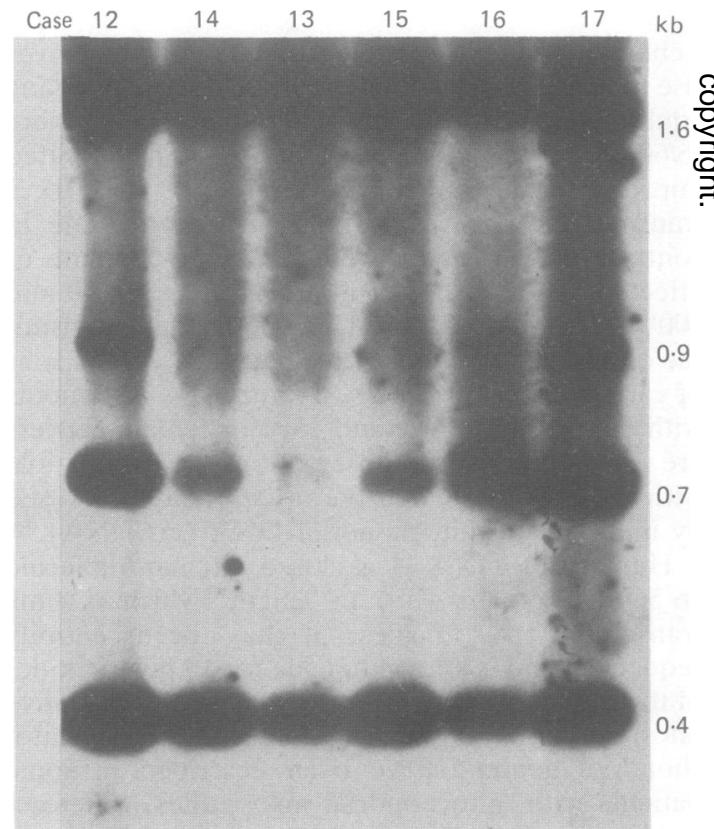

FIG 2 Restriction fragment patterns, as described in fig 1 but after 10 days' exposure, in members of family $E$ (table 1). All subjects are heteroplasmic, and the mutant mt DNA population represents more than $95 \%$ of the total $m$ t DNA (weaker signal from 0.9 and $0.7 \mathrm{~kb}$ bands) in cases 13,14 , and 15 (possible carrier, obligate carrier, and affected male respectively) but less than $80 \%$ (stronger signal from 0.9 and $0.7 \mathrm{~kb}$ bands) in cases 12,16 , and 17 (possible carrier and two unaffected males at risk; table 1$)$. 


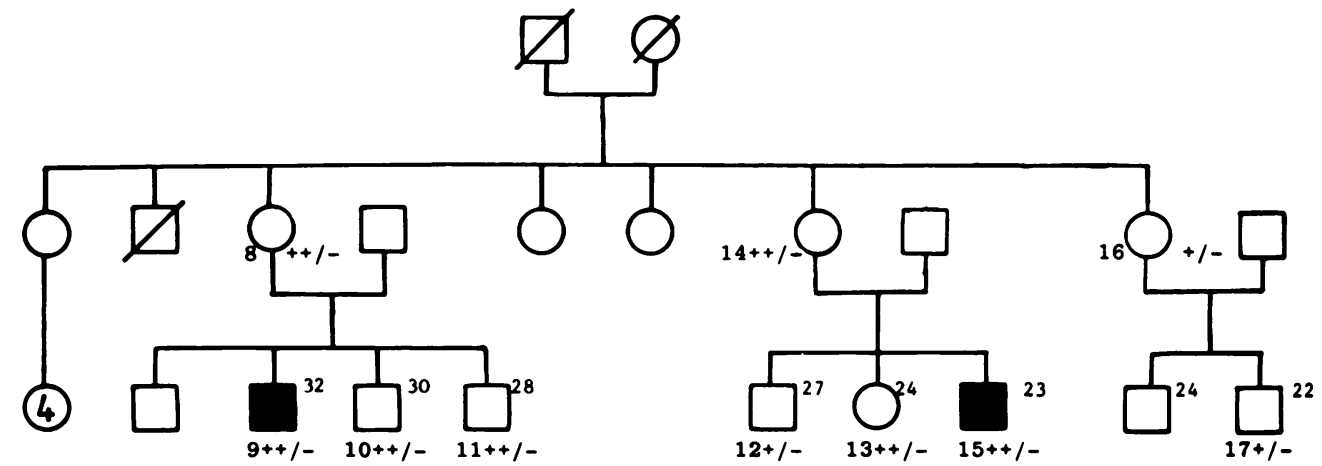

FIG 3 Pedigree of family $E$ (numbers above symbols=current age, numbers below symbols=case number in table 1 and fig $2 ; .+1-$ and $+1-$ indicate more than $95 \%$ mutant/less than $5 \%$ normal mt DNA and less than $80 \%$ mutant/more than $20 \%$ normal $m t$ DNA respectively (see fig 2 ).

\section{Results}

The SfaNI restriction site at 11778 bp was present in all 27 control subjects. It was also retained in members of four kindreds containing patients with clinically typical LHON which was maternally transmitted. In the other four LHON families, one of which contained a single case, the SfaNI site loss resulting from the mutation reported by Wallace $e t$ $a l^{13}$ was observed (fig 1 ). In the majority of subjects in these pedigrees, there was a mixture of mutant and normal mt DNA in peripheral blood (figs 1 and 2). This was not always detected after short periods

TABLE 1 Proportions of normal and mutant (11778 bp) mitochondrial DNA in members of four families with LHON.

\begin{tabular}{|c|c|c|c|c|c|c|}
\hline \multirow[t]{2}{*}{ Family } & \multirow[t]{2}{*}{ Case no } & \multirow[t]{2}{*}{ Sex } & \multirow[t]{2}{*}{ Age } & \multirow[t]{2}{*}{ Status } & \multicolumn{2}{|c|}{$M T D N A$} \\
\hline & & & & & $\begin{array}{l}\% \\
\text { Mutant }\end{array}$ & $\begin{array}{l}\% \\
\text { Normal }\end{array}$ \\
\hline A & 1 & $\mathbf{F}$ & 66 & Affected & $>95$ & $<5$ \\
\hline $\mathbf{A}$ & 2 & $\mathbf{M}$ & 41 & Affected & $>95$ & $<5$ \\
\hline $\mathbf{A}$ & 3 & $\mathbf{F}$ & 63 & Possible carrier & $>95$ & $<5$ \\
\hline $\mathbf{A}$ & 4 & $\mathbf{M}$ & 32 & At risk & $>95$ & $<5$ \\
\hline B & 5 & $\mathbf{F}$ & 25 & Affected & $>95$ & $<5$ \\
\hline C & 6 & $\mathbf{M}$ & 19 & Affected & 100 & 0 \\
\hline $\mathbf{E}$ & 8 & $\mathbf{F}$ & 66 & Obligate carrier & $>95$ & $<5$ \\
\hline $\mathrm{E}$ & 9 & $\mathbf{M}$ & 32 & Affected & $>95$ & $<5$ \\
\hline $\mathbf{E}$ & 10 & $\mathbf{M}$ & 30 & At risk & $>95$ & $<5$ \\
\hline $\mathbf{E}$ & 11 & $\mathbf{M}$ & 28 & At risk & $>95$ & $<5$ \\
\hline $\bar{E}$ & 12 & $\mathbf{M}$ & 27 & At risk & 77 & 33 \\
\hline $\mathbf{E}$ & 13 & F & 24 & Possible carrier & $>95$ & $<5$ \\
\hline$\overline{\mathbf{E}}$ & 14 & $\mathbf{F}$ & 60 & Obligate carrier & 97 & 3 \\
\hline $\bar{E}$ & 15 & $\mathbf{M}$ & 23 & Affected & 96 & 4 \\
\hline $\mathbf{E}$ & 16 & $\mathbf{F}$ & 56 & Possible carrier & 79 & 21 \\
\hline $\bar{E}$ & 17 & $\mathbf{M}$ & 22 & Probably at risk & 68 & 32 \\
\hline
\end{tabular}

For males, at risk indicates normal, with affected brothers and other matroclinal relatives; probably at risk indicates normal, with no affected brothers but other affected matroclinal relatives. For females, obligate carrier indicates two affected sons or one affected son and affected brother and/or uncle/cousin; possible carrier indicates affected brothers and/or uncles/nephews, no affected sons. of autoradiography, but became obvious after two to seven days' exposure in all but one affected male (case 6). In the other three affected males, both female patients, three males at risk of LHON, two normal carrier females with affected sons, and two possible carriers, the estimated proportion of mutant mt DNA was greater than $95 \%$ (figs 2, 3, table 1). In two males at risk aged 22 and 27 , and a potential carrier female with two healthy sons, the proportion of mutant mt DNA was less than $80 \%$.

The clinical features of these families are shown in table 2. In the four families without the $11778 \mathrm{bp}$ mutation, there were five affected males with disease durations of four years or longer. Four of these had recovered vision, to a functionally significant extent, after periods ranging between one and

TABLE 2 Clinical features of LHON patients with and without detectable mitochondrial DNA mutation (11778 bp).

\begin{tabular}{|c|c|c|c|c|c|c|c|c|}
\hline \multirow{2}{*}{$\begin{array}{l}\text { Family/ } \\
\text { case } \\
\text { no }\end{array}$} & \multirow{2}{*}{$\begin{array}{l}\text { Age at } \\
\text { onset } \\
(y)\end{array}$} & \multirow{2}{*}{$\begin{array}{l}F / U \\
(y)\end{array}$} & \multicolumn{2}{|c|}{ Ist $V A$} & \multicolumn{2}{|c|}{ Last VA } & \multirow[t]{2}{*}{$F H$} & \multirow[t]{2}{*}{ FH recovery } \\
\hline & & & $R$ & $L$ & $R$ & $L$ & & \\
\hline \multicolumn{9}{|c|}{ Cases with mt DNA mutation at 11778} \\
\hline A1 & 44 & 19 & CF & CF & CF & $6 / 60$ & + & No (eg case 2 ) \\
\hline A2 & 37 & 6 & CF & $\mathrm{CF}$ & CF & CF & + & No (case 1) \\
\hline B5 & 25 & 0.5 & $\mathrm{CF}$ & $\mathrm{CF}$ & CF & CF & + & No \\
\hline C6 & 19 & 0 & HM & HM & - & - & - & - \\
\hline E9 & 20 & 10 & HM & CF & CF & CF & + & No (case 15) \\
\hline E15 & 19 & 4 & $2 / 60$ & $3 / 60$ & $2 / 60$ & $6 / 60$ & + & No (case 9) \\
\hline \multicolumn{9}{|c|}{ Cases without mt DNA mutation at 11778} \\
\hline D7 & 31 & 4 & $6 / 60$ & $6 / 60$ & $6 / 60$ & $6 / 36$ & + & Yes (brother) \\
\hline F18 & 13 & 11 & $2 / 60$ & $\mathrm{CF}$ & $6 / 4$ & $6 / 5$ & + & Yes (uncles) \\
\hline F19 & 21 & 0.5 & $6 / 18$ & $6 / 4$ & $3 / 60$ & $3 / 60$ & + & Yes (case 18) \\
\hline G20 & 17 & 10 & $\mathrm{CF}$ & $\mathrm{CF}$ & $6 / 6$ & $6 / 9$ & + & Yes (case 22) \\
\hline G21 & 21 & 4 & $1 / 36$ & $1 / 60$ & $6 / 18$ & $6 / 12$ & + & Yes (case 21) \\
\hline G22 & 25 & 3 & $3 / 60$ & $1 / 60$ & $3 / 60$ & $1 / 36$ & + & Yes (case 21,22 ) \\
\hline $\mathbf{H} 23$ & 32 & 6 & $6 / 18$ & $6 / 60$ & $6 / 9$ & $1 / 60$ & + & Yes (brother) \\
\hline
\end{tabular}

$\mathrm{F} / \mathrm{U}=$ follow up period, VA visual acuity (1st at presentation, last at last assessment), FH family history, $\mathrm{R}$ right, $\mathrm{L}$ Left, CF able to count fingers, HM able to see hand movements. 
four years. The fifth patient (case 7) had persistent severe visual loss after four years; his affected brother had recovered 30 months after onset. The two patients who had been followed for less than four years (cases 19 and 22) both had affected brothers who had regained useful vision. In contrast, the four patients with the 11778 bp mutation who had developed blindness four years or more before study had not shown any signs of recovery. None of the affected relatives of these patients had regained useful vision.

\section{Discussion}

This study indicates that LHON is genetically heterogeneous, associated with a mitochondrial DNA mutation at position 11778 detected by $S f a$ NI in only four of eight families. It is unlikely that this mutation is a chance association with LHON, as it has not been observed in 72 control subjects from a variety of racial backgrounds ( ${ }^{13}$ and this study). Conversely, the mutation has been found in LHON pedigrees from the USA (both black and caucasoid), Canada, and Finland in the previous report ${ }^{13}$ and from Greece, England, and Ireland in the present study. Detection of this by simple Southern blotting techniques is potentially useful in clinical practice and can be used as a confirmatory test, particularly in patients without affected relatives (as in case 6). However, we have shown that the absence of the SfaNI site loss does not exclude a diagnosis of LHON as defined currently.

Un the basis of our clinical data, we tentatively suggest that the $S f a \mathrm{NI}$ site loss is associated with a poor prognosis in LHON. Recovery of useful visual function was not observed in members of any of the four families with this mutation, but had occurred in all four of the families in which the SfaNI site was intact. There can be no reasonable doubt about the diagnosis of LHON in these cases; the clinical features were typical and the pedigrees indicated maternal inheritance. The molecular basis for LHON in these kindreds, and the two previously reported, ${ }^{13}$ is unclear. The disease may be caused by a heterogeneous group of defects of respiratory chain subunits, involving either ND4 or other mitochondrially encoded polypeptides. This can only be resolved by further mt DNA sequence analysis in LHON families without the $11778 \mathrm{bp}$ mutation. The amino acid change associated with this mutation could not occur without loss of the SfaNI site. A previous study of this series of patients, including those without the $11778 \mathrm{bp}$ mutation, failed to show mt DNA deletions or any significant restriction fragment length polymorphisms. ${ }^{16}$ It is possible that some cases of
LHON have a population of mt DNA with the 11778 bp mutation, which is largely confined to affected tissues; this is true of deleted mt DNAs in the mitochondrial myopathies. ${ }^{10}$

It is not clear how an amino acid change in a subunit of complex I of the respiratory chain causes the development of subacute blindness in young adults. The selective nature of the disease is particularly difficult to explain as, although heteroplasmic, the LHON mt DNA mutation is present in a high proportion of leucocyte mt DNAs. It is of interest that Parker et al $^{17}$ have recently reported reduced NADH CoQ reductase (complex I) activity in platelets from an unusual family, some members of which had typical LHON. Others had clinical features suggesting a diagnosis of mitochondrial encephalomyopathy, including stroke-like episodes, a syndrome described in association with complex I defects. It is important to establish whether these patients have the LHON mt DNA mutation, and also if members of more typical LHON families with this mutation have systemic NADH CoQ reductase deficiency. The preponderance of affected males in LHON families is compatible with, but not explained by, an mt DNA mutation. It is possible that environmental factors such as cigarette smoking are relevant in this context. ${ }^{13}$

A variable mixture of mutant and normal mta DNA in peripheral blood (heteroplasmy) was evi? dent in all but one subject (case 6) from pedigrees showing the SfaNI site loss in the present study. The possibility that case 6 has heteroplasmy not detected by Southern blotting cannot be excluded. The findings are not explicable on the basis of partial digestion by $S f a \mathrm{NI}$; this would only be possible if none of the patients had the $11778 \mathrm{bp}$ mutation, as this leads to a site loss rather than a gain. Similar restriction fragment patterns were observed after digestion with a tenfold excess of enzyme, and were not seen in control subjects analysed on the same gels as the patients. It is also unlikely that the 0.7 and $0.9 \mathrm{~kb}$ bands represent nuclear homologies. Although human nuclear sequences homologous to parts of ND4 have been reported, ${ }^{18}$ these were at most 900 bp in length, usually substantially shorter, and contained substitutions for approximately $20 \%$ of bases. Hybridisation of mt DNA to nuclear ND4 sequences was not observed with high temperature washes. A homologous sequence of at least $1.6 \mathrm{~kb}$ in length, retaining three $S f a$ NI sites, would be required to explain our data. The strong hybridisation signal of the $0.7 \mathrm{~kb}$ fragment seen in several members of the LHON families (figs 1 and 2) after repeated washing of filters at $65^{\circ} \mathrm{C}$, and the inverse correlation between the density of this fragment and the likelihood of manifesting or transmitting LHON, 
would also point against the detection of mitochondrial pseudogenes in nuclear DNA.

Despite the high mutation rate of $\mathrm{mt}$ DNA, ${ }^{5}$ leucocyte mt DNA heteroplasmy has only recently been recognised in man, in three cases of mitochondrial myopathy to date. ${ }^{12} 19$ The mutant $\mathrm{mt}$ DNA was either duplicated or deleted in these patients, as compared to showing a point mutation in LHON. Mt DNA heteroplasmy in LHON provides a good explanation for the fact that not all sons or daughters of carrier females are affected or carriers, respectively, as would be expected if the disease mutation was homoplasmic. Wallace et al $^{13}$ concluded that their cases of LHON were homoplasmic for the 11778 bp mt DNA mutation, but heteroplasmy may have been overlooked in their study. A relatively small number of subjects from each family, particularly female carriers, was studied. The mutation was detected initially by cloning and sequencing mt DNA from one patient; cloning would reduce the chances of observing heteroplasmy. The same could apply to using DNA from transformed lymphoblasts, the source of $\mathrm{mt}$ DNA from some other subjects.

The relative proportions of mutant mt DNA found in members of the four families may have some clinical correlates. All affected males and females had at least $96 \%$ mutant mt DNA, and the same applied to unaffected women with affected sons. Less than $80 \%$ mutant mt DNA was observed in some unaffected males at risk and a female with healthy sons. Carrier females with a relatively high proportion of normal mt DNA should be less likely to transmit the disease to their sons if these findings in peripheral blood reflect the populations of $\mathrm{mt}$ DNA in ova. Similarly, the proportion of mutant $\mathrm{mt}$ DNA in the optic nerves or their vasculature could determine the likelihood of developing the disease. If confirmed after prolonged follow up of these families, and further studies of other LHON pedigrees, these observations could have useful applications in genetic counselling in this disease, which is one of the commonest causes of blindness in otherwise healthy young men.

We wish to thank Professor W I McDonald for allowing us to study his patients, Dr C J Poole for supplying some of the blood samples, Drs M King and G Attardi for the gift of the mt DNA probe, Marjory Ellison for technical assistance, and the Brain Research Trust and the Multiple Sclerosis Society of Great Britain and Northern Ireland for financial support.

\section{References}

${ }^{1}$ Nikoskelainen E, Hoyt WF, Nummelin K. Ophthalmoscopic findings in Leber's hereditary optic neuropathy. The fundus findings in the affected family members. Arch Ophthalmol 1983;101:1059-68.

2 Carroll WM, Mastaglia FL. Leber's optic neuropathy: a clinical and visual evoked potential study of affected and asymptomatic members of a six generation family. Brain 1979;102:559-80.

${ }^{3}$ Nikoskelainen E, Savontaus ML, Wanne OP, Katila MJ, Nummelin K. Leber's hereditary optic neuroretinopathy, a maternally inherited disease. Arch Ophthalmol 1987;105: 665-71.

4 Erickson RP. Leber's optic atrophy: a possible example of mitochondrial inheritance. Am J Hum Genet 1972;24:348-9.

5 Giles RE, Blanc H, Cann HM, Wallace DC. Maternal inheritance of human mitochondrial DNA. Proc Natl Acad Sci USA 1980;77:6715-9.

6 Anderson S, Bankier AT, Barrell BG, et al. Sequence and organisation of the human mitochondrial genome. Nature 1981;290:457-65.

7 Yatscoff RW, Goldskin S, Freedman KB. Conservation of genes coding for proteins synthesised in human mitochondria. Somat Cell Genet 1978;4:633-45.

8 Chomyn A, Mariottini P, Cleeter MWJ, et al. Six unidentified reading frames of human mitochondrial DNA encode components of the respiratory chain NADH dehydrogenase. Nature 1985;314:592-7.

9 Chomyn A, Mariottini P, Cleeter MWJ, et al. Functional assignment of the unidentified reading frames of human mitochondrial DNA. In: Quagliariello et al, eds. Achievements and perspectives of mitochondrial research. Vol II. Biogenesis. Amsterdam: Elsevier Science, 1985:259-75.

10 Holt IJ, Harding AE, Morgan-Hughes JA. Deletions of mitochondrial DNA in patients with mitochondrial myopathy. Nature 1988;331:717-9.

11 Zeviani M, Moraes CT, DiMauro S, et al. Deletions of mitochondrial DNA in Kearns-Sayre syndrome. Neurology (Minneap) 1988;38:1339-46.

12 Poulton J, Deadman ME, Gardiner RM. Duplications of mitochondrial DNA in mitochondrial myopathy. Lancet 1989;i: 236-40.

13 Wallace DC, Singh G, Lott MT, et al. Mitochondrial DNA mutation associated with Leber's hereditary optic neuropathy. Science 1988;242:1427-30.

14 Old JM. Fetal DNA analysis. In: Davies KE, ed. Human genetic diseases: a practical approach. Oxford: IRL Press, 1986:1-17.

15 Feinberg AP, Vogelstein B. A technique for radiolabelling DNA restriction endonuclease fragments to high specific activity. Anal Biochem 1983;132:6-13.

16 Holt IJ, Miller DH, Harding AE. Mitochondrial DNA polymorphism in Leber's optic atrophy. J Neurol Neurosurg Psychiatry 1988;51:1075-7.

17 Parker WD, Oley CA, Parks JK. A defect in mitochondrial electron transport activity (NADH:coenzyme Q oxidoreductase) in Leber's hereditary optic neuropathy. N Engl J Med 1989;320: 1331-3.

18 Fukuda M, Wakasugi S, Tsuzuki T, Nomiyama H, Shimada K. Mitochondrial DNA-like sequences in the human nuclear genome. J Mol Biol 1985;186:257-66.

19 Johns DR, Drachman DB, Hurko O. Identical mitochondrial DNA deletion in blood and muscle. Lancet 1989;i:393-4.

Correspondence to Dr A E Harding, University Department of Clinical Neurology, Institute of Neurology, Queen Square, London WC1N 3BG. 